\title{
Waste separation intention of China's urban residents and its influencing factors
}

\section{Sun Y.*}

Commercial College, Xijing University, Xi'an 710123, China

Received: 02/07/2020, Accepted: 18/08/2020, Available online: 22/10/2020

*to whom all correspondence should be addressed: e-mail: 723240327@qq.com

https://doi.org/10.30955/gnj.003383

\section{Graphical abstract}

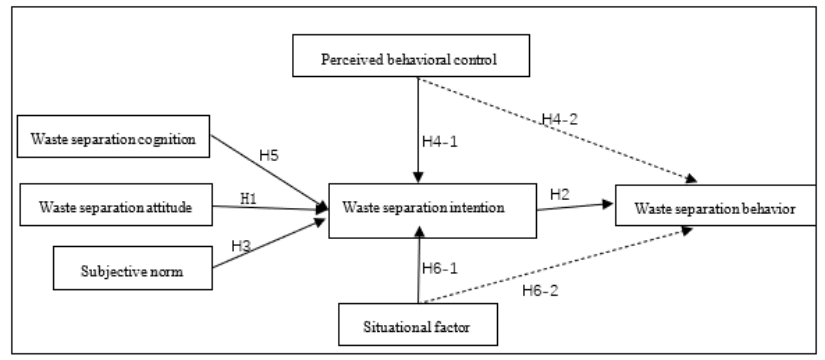

\begin{abstract}
Urban household waste causes serious pollution of the urban ecological environment. Waste separation and processing is an effective approach to reduce the ecological environment damage caused by household waste. From the perspective of the source of urban household waste separation, this paper investigates the influencing factors of the willingness of urban residents to separate household waste based on the theory of planned behavior. Through regression analysis, it was found that: Firstly, waste separation attitude, waste separation cognition, subjective norm, perceived behavioral control, and situational factors have significant positive impacts on the willingness of urban residents to separate waste, and the degrees of these impacts show a decreasing order; Secondly, the willingness to separate waste has a significant positive impact on the implementation of urban residents' actions to separate waste.
\end{abstract}

Keywords: Urban resident, the willingness to separate waste, the theory of planned behavior.

\section{Introduction}

In recent years, China has made tremendous efforts to protect and improve the environment, and remarkable outcomes have been accomplished. However, there are still many environmental problems, especially urban household waste, which is generated at an increasing rate and becomes increasingly complex. Household waste not only occupies a large amount of land but also destroys the urban landscape. Moreover, it has caused continuous pollution to the environment, posing a threat to public health. Collection and separation of urban household waste is a key step to resolving the "garbage siege", to improve the urban ecological environment, and to promote the recycling of resources. This process refers to collecting and separating the waste at the source according to different waste disposal requirements, and the separated waste can then be processed based on the corresponding methods to reduce the waste and environmental pollution and to maximize the usage of natural resources (Hong et al., 2018). In 1992, the State Council of the People's Republic of China stated "the urban household waste should be gradually collected, transported and disposed of" for the first time in the Regulations on the Administration of City Appearance and Environmental Sanitation (State Council Order [1992] No. 101) (Fan et al., 2019). Since then, China has promoted the separation and collection of household waste for many times: In 2000, the former Ministry of Construction of the People's Republic of China identified eight cities, including Shanghai, as "the pilot cities for the recycling of household waste". However, not long after the first trial, this project was not continued in most of these cities. After 2010, Beijing, Nanjing, Guangzhou, Shanghai, and other cities in China successively promoted the pilot project of household waste separation and collection, and innovative experiences and promotion models gradually formed. However, public participation was not active. In December 2016, Chinese President Xi Jinping presided over the Central Leading Group for Financial and Economic Affairs to investigate the general implementation of the waste separation system. In March 2017, the State Council of the People's Republic of China introduced that "the first compulsory separation of household waste in certain cities", and Beijing and Shanghai launched mandatory waste separation policies in public institutions. In July 2019, the mandatory separation of domestic waste began to be fully implemented in Shanghai, China. The Ministry of Housing and Urban-Rural Development of the People's Republic of China proposed that before 2025, the waste separation and recycling system should be completed in prefectural level cities. The separation and recycling of urban household waste have become a general trend, 
which cannot be avoided. To conquer the challenge of separation and recycling of urban household waste, however, processing the waste in the waste management centers is not enough and more actions need to be taken at the sources of the waste. Studies have shown that separating household waste at the sources is a premise of effectively managing household waste and realizing the goal of harmlessness waste management, resource recycling, and household waste reduction in cities. It is also the most effective means to improve the urban ecological environment and to strengthen the recycling of the urban household waste in China.

\section{Literature review}

Urban household waste, one of the major environmental problems, has received widespread attention from all over the world. Separating household waste at the sources by changing the "all in one" waste disposal habit of urban residents is a big challenge (Du et al., 2020). Due to the difficulty for urban residents to develop the habit of waste separation in the short term, no much progress has been made in recent trials of urban household waste separation and recycling. Studies have shown that $78.73 \%$ of urban residents occasionally separate different types of waste into different garbage bags before disposing of them in the corresponding garbage bins (Cyril et al., 2019; Jiang et al., 2018; Muhammad et al., 2019; Vimalraj et al., 2019).

This indicates that most residents regard the waste separation on the spur of the moment. In 2008, a survey carried out in 46 main cities in China by China's National Development Research Center of the State Council Development Research Center also showed that only $38.3 \%$ of families separate household waste based on their categories (Ministry of Housing, 2019). The difficulties in developing the household waste separation habit of urban residents mainly are shown in two aspects. Firstly, urban residents do not have enough understanding of waste separation and lack of knowledge for the development of proper waste separation habits. For example, a survey of household waste separation, which was carried out in 17 cities including Beijing, Shanghai, and Guangzhou, revealed that only $27.7 \%$ of the questions were answered correctly (Chen, 2019). Secondly, the behavioral pattern of residents in household waste separation is difficult to unify. Most residents are both community members and workers and these two identities have inconsistent goals in waste separation, which restricts the development of the habit of household waste separation (Iffah and Azura, 2019; Nisha et al., 2020; Paramasivam and Siddan, 2020; Zephania et al., 2019).

Currently, in related academic researches, the studies on household wastes separation have been changed from the technology perspective to the social psychology perspective (Chen et al., 2012). Most western scholars have conducted in-depth analyses of the process of household waste separation to identify the influencing factors of this behavior, which can then be used to analyze the correlation between the residents' intention and attitude towards household waste separation. These results have great significance to regulate, direct, and cultivate residents' behavior in household waste separation (Khoo et al., 2019; Liu et al., 2010; Pomponi et al., 2018; Teixeira et al., 2004). Moreover, it also provides a powerful theoretical basis for formulating policies for household waste management and promoting the recycling and utilization of household waste (Akaninyene et al., 2020; Hassan et al., 2019; Pipas and Varun, 2019; Prabal and Syed, 2020; Singhabhandhu et al., 2010).

At present, in the western academic sector, in the studies on household waste management behavior, especially in the studies of the process of household waste recycling in the perspective of social psychology, many scholars have conducted in-depth analyses of waste classification behavior to explore the influencing factors of household waste separation and to investigate urban residents' awareness and attitudes during the process of waste separation (Wang, 2017). These results play an extremely important role in guiding and promoting the habit of household waste separation (Hwang et al., 2017; Knussen et al., 2004).

Currently, the commonly used theories and models in related researches are Ajzen and Fishbein's theory of planned behavior and theory of reasoned action, Ellis' $A B C$ model, Triandis's theory of interpersonal relations, the household waste management behavior model, and the resident waste management model. The scholars, who construct these theories, proposed the factors that ultimately affect their corresponding behaviors based on regional characteristics and the scopes of their researches. Although there are many similarities in these existing theories and models, each of them has its own advantages and disadvantages. Besides, they have different factors that influence the variables of the final behavior and the way how these factors influencing these behaviors are also various.

\section{Analysis framework and hypotheses}

\subsection{Analysis framework}

Based on Ajzen's theory of planned behavior, interviews with experts, and the studies of the theory of interpersonal relations, the cognitive and contextual factors and perceived behavior control of waste classification are explored. These three variables influence waste separation intention and play a significant role in the process of household waste separation. This paper aims to explore these three factors' influence on waste separation intention and to identify the causes of the differences in waste separation. The final research framework is shown in Figure 1.

\subsection{Hypotheses}

Based on our literature review, most scholars have confirmed that, in the theoretical studies of behavior, attitudes can directly affect the intention of individuals to implement environmentally friendly behaviors. Besides, those who have a very positive attitude towards waste separation generally are more willing to implement the behavior of waste separation, and the possibility of 
implementing waste separation behavior is greater. In this regard, the hypothesis proposed in this study is: the attitude of household waste separation has a certain influence on waste separation intention and indirectly affects the waste separation behavior.

H1: The attitude of waste separation has a direct and positive impact on waste separation intention.

H2: Waste separation intention has a direct and positive impact on waste separation behavior.

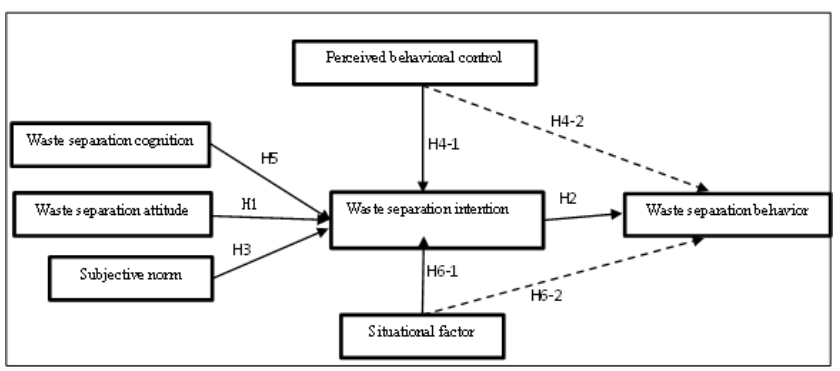

Figure 1. Research framework and hypothesis

Note: The path indicated by the dotted line in the figure is not supported by the following data analysis.

The subjective norm is appealing and emphasizing the waste separation in front of important individuals and reference group members. It also refers to the pressure that individuals face during the process of waste separation. Moreover, the behavior of the surrounding group members has an exemplary effect, which is the influence of the surrounding group members on an individual's behavior. If the people around an individual start to implement waste separation behavior, they usually have a certain impact on the individual, raising his/her intention to separate waste. Therefore, the following hypothesis is proposed:

H3: Subjective norms of individuals have a direct and positive impact on waste separation intention.

Perceived behavioral control refers to the obstacles to separate waste and the degree of perception among facilitating factors, which directly affect waste separation intention and whether the action of waste separation can be implemented. In other words, an individual with a high intention to separate waste may not perform the action of waste separation, and the perceived behavior of the corresponding waste separation has a strong connection between promoting factors or hindrance factors. When these hindering factors of waste separation perceived by an individual are smaller or the promoting factor is larger, the realization of waste separation intention becomes more accessible, and vice versa. Therefore, in this study, the following hypothesis is proposed:

H4: Perceived behavioral control has a direct and positive impact on waste separation intention (H4-1) and waste classification behavior (H4-2).

Waste separation cognition refers to the individual's understanding of the process, status, and methods of waste separation. Individuals' knowledge of waste separation behavior has a direct impact on their final intention to separate waste. If an individual knows nothing about the process, status, and method of separating household waste, the individual's action to separate household waste is impossible to be realized. The variables of individuals' waste separation cognition have different influences on the variables of waste separation intention. Therefore, the following hypothesis is proposed:

H5: Waste separation cognition has a direct and positive impact on waste separation intention.

Situational factors refer to external factors that have an impact on individuals' waste separation behavior, including propagandas, facilities, and policies for waste separation. If the situational factors are very favorable, residents will be more likely to show a relatively positive attitude towards waste separation and individuals will have stronger influences on waste separation intention. Eventually, it is easier for individuals to form waste separation behaviors. Hence, the following hypothesis is proposed:

H6: Situational factors have a direct and positive impact on waste separation intention (H6-1) and waste separation behavior (H6-2), though the degree of impacts varies.

\section{Methods}

\subsection{Sample collection}

The research object of this study is the influencing factors of urban residents' intention to separate waste. The survey was carried out in two approaches: the in-person survey and the online survey. A total of 500 questionnaires were sent out. 150 of these questionnaires were sent through online channels, including the WeChat friend circle, QQ group, and Weibo, and 350 of these questionnaires were in-person surveys. A total of 467 collected questionnaires were valid and the recovery rate was $93.4 \%$. A total of 338 collected questionnaires were obtained through the inperson survey method, accounting for $72.4 \%$ of the valid questionnaires; the rest of the collected questionnaires were collected through the online channels, accounting for $27.6 \%$ of the valid questionnaires. The basic characteristics of the respondents are summarized in Table 1.

\subsection{Questionnaire design and variables}

The questionnaire used in this study consists of seven Likert scales and a set of multiple-choice questions. It will take about 15 minutes to complete. All these scales have been used in published literature and they were translated from English to Chinese. The accuracy of the translation was check by translating them back to English. Before the formal survey, a pre-survey of the statements and questions in the questionnaire was conducted with 35 residents in Xian, China. Some phrases in the questionnaire were modified based on the feedback.

In this study, the waste separation behavior scale ( $a=0.907)$ contains one item, which is used to quantify the waste separation behavior of urban residents. The waste separation intention scale $(a=0.846)$ measures the psychological commitment of the waste separation behavior of urban residents. The situational factor scale $(a=0.799)$ measures external factors that influencing urban residents' implementation of waste separation behavior, 
which includes facilities, propagandas, systems, and policies. The perceived behavioral control scale ( $a=0.857)$, including time and convenience, covers the factors that promote urban residents' implementation of waste separation behavior. The subjective norm scale $(a=0.893)$ evaluates the influence of weather celebrities or famous groups adopting the waste separation habit on the behaviors of urban residents. The waste separation attitude scale $(a=0.823)$ measures the subjective assessment of urban residents on waste separation. The waste separation cognitive scale $(a=0.877)$ assesses the extent to which urban residents understand and aware of the process and status of waste separation. In terms of reliability, the values of all these scales exceed 0.7 . In addition, the confirmatory factor analyses of the average Table 1. Basic characteristics of the respondents

\begin{tabular}{|c|c|c|c|}
\hline & Characteristic & Count & Percentage \\
\hline \multirow{2}{*}{ Gender } & Male & 225 & 48.18 \\
\hline & Female & 242 & 51.82 \\
\hline \multirow{3}{*}{ Marital status } & Married & 315 & 67.452 \\
\hline & Unmarried & 134 & 28.694 \\
\hline & Other & 18 & 3.854 \\
\hline \multirow{5}{*}{ Age } & Under 20 years old & 37 & 7.923 \\
\hline & 21-30 years old & 98 & 20.985 \\
\hline & $31-40$ years old & 205 & 43.897 \\
\hline & 41-50years old & 72 & 15.418 \\
\hline & Above 50 years old & 55 & 11.777 \\
\hline \multirow{4}{*}{ Education } & High school and below & 54 & 11.563 \\
\hline & College & 169 & 36.188 \\
\hline & Bachelor & 175 & 37.474 \\
\hline & Master degree and above & 69 & 14.775 \\
\hline \multirow{4}{*}{ Annual income } & Below 50k yuan & 97 & 20.771 \\
\hline & 50k-100k yuan & 206 & 44.111 \\
\hline & 110k-200k yuan & 114 & 24.411 \\
\hline & Above $200 k$ yuan & 50 & 10.707 \\
\hline
\end{tabular}

Table 2. Reliability of each variable in the questionnaire

\begin{tabular}{cccc}
\hline Variable & Cronbach's a & CR & AVE \\
\hline Waste separation cognition & 0.877 & 0.903 & 0.609 \\
\hline Waste separation attitude & 0.823 & 0.891 & 0.59 \\
\hline Subjective norm & 0.893 & 0.924 & 0.828 \\
\hline Perceived behavioral control & 0.857 & 0.906 & 0.724 \\
\hline Situational factor & 0.799 & 0.848 & 0.696 \\
\hline Willingness to separate waste & 0.846 & 0.896 & 0.706 \\
\hline Waste separation behavior & 0.907 & 0.941 & 0.801 \\
\hline
\end{tabular}

\section{Results and discussion}

In data analysis, the regression analysis method was employed to assess each hypothesis of the factors that affect the waste separation behavior of urban residents, and the results are shown in Tables 3 and 4 . The R-square is a measure of the overall explanatory power. Generally, if the R-square of a model is greater than 0.1 , the explanatory power of the model is acceptable. In this regression analysis, the $\mathrm{R}$-square of this model is 0.178 , indicating that the explanatory power of this model is excellent. The significance level of the path coefficient of a model is determined based on the P-value. When the significance level is $0 \leq P<0.001$, the path has a high significance level, variance extracted (AVE) and the composite reliability (CR) of each variable were carried out with AMOS (Version 7.0) to further assess the reliability of the scale. The AVE value and the CR value of each variable are greater than 0.5 and 0.7 , respectively, indicating that these scales have good reliability. For validity analysis, the fitting parameters are $\mathrm{x} 2 / \mathrm{df}=1.91, \mathrm{CFI}=0.94, \mathrm{TLI}=\mathrm{D}$ 0.92, NFI=0.89, RMSEA=0.077. The standard loadings of the factors of all these items in the questionnaire are greater than the minimum requirement of 0.5 and are significant at the 0.001 level, indicating a high degree of convergent validity. Besides, the AVE values of the seven variables are all greater than the square of the correlation coefficients of other factors, suggesting that these variables have good discriminant validity (Table 2 ). 
intention to separate waste. Waste separation intention $\left(P=0.456\right.$, significance level: $\left.{ }^{* * *}\right)$ has a significant positive impact on the waste separation behavior of urban residents. The influence of situational factors and perceived behavioral control on the waste separation behavior of urban residents are insignificant. Hence, the hypothesis, $\mathrm{H} 2$, is accepted, and the hypotheses, $\mathrm{H} 4-2$ and $\mathrm{H} 6-1$, are rejected, indicating that the intention of rural residents to separate waste has a direct positive impact on waste separation behavior.

\section{Conclusions}

This study is based on the theory of planned behavior to assess the influencing factors of the intention of urban residents to separate household waste. The process of influencing factors of urban residents' intention to separate household waste is in line with the theory of planned behavior. The waste separation intention of urban residents participated in this survey has a strong positive impact on waste separation behavior. As be proven by the analysis results, other variables have no significant effect on the waste separation behavior, which further indicates that the analyzing process of the factors affecting the intention to separate household waste is in line with the research hypotheses of the theory of planned behavior. In other words, when urban residents' intention to separate waste is satisfied, the waste separation behavior of urban residents will eventually be implemented.
In the process of household waste separation, waste separation attitude and waste separation cognition are the main factors that affect urban residents' intention to separate waste. Based on the data obtained from the regression analysis, the degrees of positive impacts of waste separation attitude, waste separation cognition, subjective norm, perceived behavioral control, and situational factors on urban residents' intention to separate waste show a decreasing order. In the attitudebehavior-context theory, when waste separation behavior is difficult to implement, or the cost and time required for the implementation of waste separation behavior are relatively high (In other words, the situational factors make the implementation of waste separation behavior inconvenient), waste separation behavior will still occur if waste separation attitude is very positive. Based on the analysis results, the situational factors and perceived behavioral control are control variables and they have no direct positive impact on waste separation behavior. However, the significance level of their positive impacts on waste separation intention is very high, suggesting that waste separation intention is an intermediate variable in the process of waste separation. The influence of any influencing factors (waste separation attitude, waste separation cognition, subjective norm, perceived behavioral control, and situational factors) on waste separation intention can indirectly affect the implementation of waste separation behavior.

Table 3. Regression analysis results of independent variables of waste separation intention

\begin{tabular}{ccc}
\hline Independent variable & $\boldsymbol{\beta}$ & Significance level \\
\hline Waste separate attitude & 0.240 & $* *$ \\
\hline Subjective norm & 0.187 & $* *$ \\
\hline Perceived behavioral control & 0.163 & $* *$ \\
\hline Situational factor & 0.152 & $* *$ \\
\hline Waste separation cognition & 0.201 & $* * *$ \\
\hline
\end{tabular}

Table 4. Regression analysis results of independent variables of the waste separation behavior

\begin{tabular}{ccc}
\hline Independent variable & $\boldsymbol{\beta}$ & Significance level \\
\hline Perceived behavioral control & 0.109 & Insignificant \\
\hline Situational factor & 0.037 & Insignificant \\
\hline Waste separation intention & 0.456 & $* * *$ \\
\hline
\end{tabular}

\section{References}

Akaninyene I.A., Ibiam I.E., Nnaemeka H.O. and Nzube T.E. (2020), Dynamics of phosphatase enzyme and microbial properties in a degraded ultisol amended with animal manures, Journal Clean WAS, 4(1), 21-27.

Chen L.F., Wu G., Zhang Y., et al. (2012), The research status and critical problem of the waste classified recovery behavior, Ecological Economy, 142-145.

Chen Y. (2019), Grasp garbage classification should be accurate measures, Ningbo Economy (Finance View), 44-45.

Cyril C.O. and Imo V. (2019), Exploration for mineralization and hydrocarbon prospecting zones of Abakiliki aspect of lower Benue trough, Acta Scientifica Malaysia, 3, 12-16. DOI:10.26480/asm.02.2019.12.16.

Du H.Z. and Liu F.R. (2020), Difficulties and countermeasures of municipal domestic waste classified collection in China, Journal of Xinjiang Normal University (Edition of Philosophy and Social Sciences), 1-11[2019-11-06]. https://doi.org/10.14100/j.cnki.65-1039/g4.20191022.001.

Fan W.Y. and Xue L.Q. (2019), Why the former domestic waste classifications have little effect concurrently discussion on the system construction in the compulsory classification era, Exploration and Free Views, 150-159+199-200.

Hassan A., Shanawar H., Yasir N., Muhammad A., Umair Y., Amna C., Ali A. and Mian W.D. (2019), Efficiency assessment of wastewater treatment plant: A case study of Pattoki, District Kasur, Pakistan, Earth Sciences Pakistan, 3(2), 1-4.

Hong C., Qin W.X. and Lu C.Y. (2018), The difficulties and countermeasures of carrying out household garbage classification and collection are discussed, Guangdong Science \& Technology, 27, 54-56.

Hwang S.H. and Yoon C.S. (2017), Main environmental factors affecting concentrations of culturable airborne bacteria in indoor laboratories over a period of one year, Applied Ecology and Environmental Research, 15, 321-333. 
Iffah N.L. and Azura A. (2019), A review on the identification and analysis of heavy metals in herbs using inductively coupled plasma mass spectrometry (ICPMS), Environmental Contaminants Reviews, 2(2), 1-5.

Jiang R.J. (2018), Investigation and analysis of source classification and collection of municipal solid waste, Resources Economization \& Environmental Protection, 105-106.

Khoo S.C., Phang X.Y., Ng C.M., et al. (2019), Recent technologies for treatment and recycling of used disposable baby diapers, Process Safety and Environmental Protection, 123, 116-129.

Knussen C., Yule F., Mackenzie J., et al. (2004), An analysis of intentions to recycle household waste: The roles of past behaviour, perceived habit, and perceived lack of facilities, Journal of Environmental Psychology, 24, 237-246.

Liu H. and Liu Z. (2010), Recycling utilization patterns of coal mining waste in china, Resources Conservation and Recycling, 54, 1331-1340.

Ministry of Housing and Urban-Rural Development. (2019-06-28), By the end of next year, 46 key cities will have completed waste separation and treatment systems. https://baijiahao. baidu.com/s?id=1637571720383348759\& $w f r=s p i d e r \& f o r=p c$.

Muhammad T.S., Hanhui Z., Muhammad A., Jia X.Y. and Li R. (2019), Effects of different type of black smoke originate from kilns on the natural environment, Journal Clean Was, 3, 1113.

Nisha P., Pragya A. and Puja T. (2020), Management of purple blotch complex of onion (Allium Cepa Cv Red Creole) under field condition in Rukum-West, Nepal, Malaysian Journal of Sustainable Agriculture, 4(2), 71-74.

Paramasivam C.R. and Siddan A. (2020), Soil fertility analysis in and around magnesite mines, Salem, India, Geology, Ecology, and Landscapes, 4(2), 140-150.

Pipas K. and Varun J. (2019), Modelling surface run-off response using hydrological model swat in the upper watershed of river Subarnarekha, India, Earth Sciences Malaysia, 3(2), 9-15. DOI: 10.26480/esmy.02.2019.09.15.

Pomponi F. and Lenzen M. (2018), Hybrid life cycle assessment (Ica) will likely yield more accurate results than process-based Ica, Journal of Cleaner Production, 176, 210-215.

Prabal B. and Syed H.R. (2020), Aquatic health index of coastal aquaculture activities at South-Eastern coast of Bangladesh, Water Conservation and Management, 4(1), 53-59.

Singhabhandhu A. and Tezuka T. (2010), Prospective framework for collection and exploitation of waste cooking oil as feedstock for energy conversion, Energy, 35, 1839-1847.

Teixeira J., Antunes A.P. and Sousa J.P.D. (2004), Recyclable waste collection planning - A case study, European Journal of Operational Research, 158, 543-554.

Vimalraj P.G., Parag M.D. and Ayush U. (2019), Developmental human interface due to train collision of Asian elephant (Elephas Maximus) in Western circle forest division, Uttarakhand, India, Environment \& Ecosystem Science, 3, 1719.

Wang X.P. (2017), Study of the classification and its resource utilization model on rural household solid waste, Hunan Agricultural University.

Zephania N.F., Suiven J.P.T. and Martin F. (2019), Eucalyptus Tree Colonization Of The Bafut-Ngemba Forest Reserve, North West Region, Cameroon. Environment \& Ecosystem Science, 3(2), 12-16. 